\title{
Application of deep learning to estimate stratospheric gravity wave potential energy
}

\author{
Yue Wu ${ }^{1,2}$, Zheng Sheng ${ }^{1 *}$, and XinJie Zuo ${ }^{3}$ \\ ${ }^{1}$ College of Meteorology and Oceanology, National University of Defense Technology, Changsha 410073, China; \\ ${ }^{2}$ Northwest Institute of Nuclear Technology, Xi'an 710024, China; \\ ${ }^{3}$ High-tech Institute, Fan Gong-ting South Street on the $12^{\text {th }}$, Qingzhou 262500, China
}

\section{Key Points:}

- A deep learning algorithm is used to estimate the stratospheric GW $E_{\mathrm{p}}$ over $20-30 \mathrm{~km}$ in the latitude range of $60^{\circ} \mathrm{S}-60^{\circ} \mathrm{N}$ using ERA5 reanalysis datasets, GMTED2010 terrain data and COSMIC RO data.

- This deep learning method can effectively estimate the zonal trend of GW $E_{\mathrm{p}}$.

- The GW $E_{\mathrm{p}}$ estimated by the deep learning model shows obvious seasonal variation and quasi-biennial oscillation.

Citation: Wu, Y., Sheng, Z., and Zuo, X. J. (2022). Application of deep learning to estimate stratospheric gravity wave potential energy. Earth Planet. Phys., 6(1), 70-82. http://doi.org/10.26464/epp2022002

\begin{abstract}
One of the most important dynamic processes in the middle and upper atmosphere, gravity waves (GWs) play a key role in determining global atmospheric circulation. Gravity wave potential energy (GW $\left.E_{p}\right)$ is an important parameter that characterizes GW intensity, so it is critical to understand its global distribution. In this paper, a deep learning algorithm (DeepLab V3+) is used to estimate the stratospheric GW $E_{\mathrm{p}}$. The deep learning model inputs are ERA5 reanalysis datasets and GMTED2010 terrain data. GW $E_{\mathrm{p}}$ averaged over $20-30 \mathrm{~km}$ from $60^{\circ} \mathrm{S}-60^{\circ} \mathrm{N}$, calculated by COSMIC radio occultation (RO) data, is used as the measured value corresponding to the model output. The results show that (1) this method can effectively estimate the zonal trend of GW $E_{\mathrm{p}}$. However, the errors between the estimated and measured value of $E_{\mathrm{p}}$ are larger in low-latitude regions than in mid-latitude regions, possibly due to the large number of convolution operations used in the deep learning model. Additionally, the measured $E_{\mathrm{p}}$ has errors associated with interpolation to the grid; this tends to be amplified in low-latitude regions because the GW $E_{\mathrm{p}}$ is larger and the RO data are relatively sparse, affecting the training accuracy. (2) The estimated $E_{\mathrm{p}}$ shows seasonal variations, which are stronger in the winter hemisphere and weaker in the summer hemisphere. (3) The effect of quasi-biennial oscillation (QBO) can be clearly observed in the monthly variation of estimated GW $E_{\mathrm{p}}$, and its QBO amplitude may be less than that of the measured $E_{\mathrm{p}}$.
\end{abstract}

Keywords: deep learning; stratospheric gravity wave; potential energy

\section{Introduction}

Atmospheric gravity waves (GWs) are mesoscale disturbances that exist in the global atmosphere and have a global propagation effect (Alexander, 1998). GWs play a key role in the coupling of the lower and upper atmosphere (Fritts and Alexander, 2003) and in the dynamics and circulation of the middle atmosphere (John and Kumar, 2012). After GWs are excited in the troposphere, the driving force generated by the upward propagation, saturation, and break-up process of GWs is an important source for the structure of the middle atmosphere (Chen D et al., 2012, 2013). It is generally accepted that GWs excited by topography, convection, and wind shear in the lower atmosphere transport momentum and energy to the middle atmosphere (Alexander, 1996), and interact with the background atmosphere and other atmospheric waves.

Correspondence to: Z. Sheng, 19994035@sina.com

Received 23 JUL 2021; Accepted 06 SEP 2021.

Accepted article online 04 NOV 2021.

(C) 2022 by Earth and Planetary Physics.
With the decrease in atmospheric density, the amplitudes of GWs increases when they propagate to the upper atmosphere after being excited in the troposphere, causing them to reach an instability saturation condition. Finally, GWs break up and transfer their momentum and energy to the background atmosphere, changing the atmospheric background state.

In the study of GWs, it is a research hotspot to obtain the potential energy $\left(E_{\mathrm{p}}\right)$, wavelength, propagation direction, momentum flux, and other parameters of GWs from sounding data (Xu XH et al., 2015). The data used to study GWs mainly come from radiosondes (Yoshiki and Sato, 2000; Kramer et al., 2016), sounding rockets (Hamilton, 1991), lidar (Zhao RC et al., 2016), and spaceborne sensors (Wang L and Alexander, 2010). Although this equipment has provided valuable measurements for the study of atmospheric GW activity, it is difficult to achieve a global distribution of GWs. Compared with data from other observation methods, satellite observation data have a wider spatial range and can be used to study the large-scale or global distribution of atmospheric GW 
parameters. Alexander et al. (2008) performed a global analysis of HIRDLS (High Resolution Dynamics Limb Sounder) temperature profile data to derive properties of gravity waves. Meyer et al. (2018) compared temperature variances of AIRS (Atmospheric InfraRed Sounder) and HIRDLS to evaluate the relationship of their stratospheric gravity wave observations. Liu X et al. (2019) studied the seasonal and height dependencies of the orographic primary and larger-scale secondary gravity waves using the temperature profiles of SABER (Sounding of the Atmosphere using Broadband Emission Radiometry).

Since the end of the 20th century, the method of measuring atmospheric parameters by Global Navigation Satellite System (GNSS) radio occultation (RO) technology has been widely used and many achievements have been made (Chen ZP et al., 2018; Cheng $\mathrm{N}$ et al., 2021). By measuring the bending angle and signal delay of the radio signal transmitted by the satellite when the signal passes through the atmosphere, the atmospheric refractivity, temperature, pressure, water vapor pressure, and ionospheric electron density profiles can be calculated (Luo J et al., 2018). GNSS RO has the advantages of high precision, high vertical resolution, all-weather observation and global coverage (Bai WH et al., 2020). This has become an important approach to global atmospheric measurement. In investigations of GWs using GNSS RO data, Xu XH et al. (2018) determined the spatial and temporal variability of global stratospheric GWs and the characteristics of GW activity during sudden stratospheric warming (SSW) using COSMIC RO data.

In recent years, deep learning has played an important role in investigations of weather and climate prediction (Rasp et al., 2018; Scher, 2018; Moraux et al., 2019). However, there are still few studies using deep learning to estimate atmospheric GW parameters. Only Matsuoka et al. (2020) used 29-year reanalysis datasets to estimate the flux of GWs near the Hidaka Mountains in Japan using deep learning. Although reanalysis datasets can cover the world horizontally and have high horizontal resolution, their vertical resolution is generally low and cannot be used solely by deep learning to obtain gravity wave potential energy (GW $E_{\mathrm{p}}$ ). Matsuoka et al. (2020) innovatively applied deep learning to estimate GW parameters, but due to the small region that was selected, it could not reflect the spatial and temporal variability of global GW activity.

Taking ERA5 global reanalysis datasets and terrain data as input and taking the global GW $E_{\mathrm{p}}$ calculated by COSMIC RO data as the label, this study applies deep learning (DeepLab V3+) to estimate the GW $E_{\mathrm{p}}$ averaged over $20-30 \mathrm{~km}$ in the latitude range of $60^{\circ} \mathrm{S}-60^{\circ} \mathrm{N}$ as the output of the model. Additionally, this study verifies that $\mathrm{GW} E_{\mathrm{p}}$ estimated by the trained model has significant seasonal variation and quasi-biennial oscillation (QBO).

Generally, COSMIC RO data can be used to study GW activity only after 2007, while the global distribution of GW $E_{\mathrm{p}}$ before 2007 cannot be determined. The significance of this study is to estimate the GW $E_{\mathrm{p}}$ in recent decades by using a large number of reanalysis datasets to understand the long-term distribution of GWs in middle and low latitudes.

\section{Datasets}

\subsection{Reanalysis Datasets}

ERA5 is the fifth generation European Centre for Medium-Range Weather Forecasts (ECMWF) reanalysis for global climate and weather. The input data of the deep learning model in this study are mainly the atmospheric parameters of ERA5 at certain pressure levels.

Since the excitation conditions of GWs mainly include terrain, wind shear, and deep convection, the input parameters of ERA5 selected in this study include temperature, $u$-component of wind (zonal wind), $v$-component of wind (meridional wind), vertical velocity, and relative humidity at 500, 700 and $850 \mathrm{hPa}$. To enable the deep learning model to learn the QBO characteristics of GWs, the input should include some atmospheric parameters with QBO characteristics; thus, temperature and zonal wind at 50, 100 and $200 \mathrm{hPa}$ are appended to the model input.

\subsection{Terrain Data}

Terrain is key to the excitation of GWs, so global mean elevation data are used as the input to the deep learning model. The Global Multi-resolution Terrain Elevation Data 2010 (GMTED2010) used in this study is an enhanced global elevation model developed by the U.S. Geological Survey (USGS) and the National Geospatial-Intelligence Agency (NGA).

\subsection{COSMIC RO Data}

The COSMIC mission is an Earth atmosphere detection system using low-orbit satellites to study weather forecasting, atmospheric processes, climate monitoring, model verification, space weather, ionospheric research, etc. The high accuracy and vertical resolution ( $20 \mathrm{~m}$ in the L2 data) of COSMIC RO data enable the calculation of the global GW $E_{\mathrm{p}}$. This paper uses COSMIC RO data to calculate the GW $E_{\mathrm{p}}$ averaged over $20-30 \mathrm{~km}$ as the measured values applied in the training process.

\section{Method}

For the sake of simplicity, in this paper the GW $E_{\mathrm{p}}$ calculated by COSMIC RO data is called the measured value, and the GW $E_{\mathrm{p}}$ output by the deep learning model is called the estimated value.

\subsection{Calculation of GW $E_{\mathrm{p}}$ with COSMIC RO}

The key to GW calculation is to extract the perturbation of the temperature profile caused by GWs. This paper refers to the method developed by Wang $L$ and Alexander (2009) to obtain the temperature perturbation with COSMIC RO data, similar to that used in many related studies (Wang $L$ and Alexander, 2010; $\mathrm{Xu} \mathrm{XH}$ et al., 2015, 2018; Zeng XY et al., 2017). The procedure is as follows:

(a) Interpolation. The cubic spline interpolation method is used to interpolate the profile data over $8-38 \mathrm{~km}$ in altitude to a regular $200 \mathrm{~m}$ resolution.

(b) Elimination of abnormal profile data. There are still some abnormal temperature profiles in the COSMIC L2 data (Figure 1a). To avoid the effects of these abnormal profiles on the subsequent calculation of GW $E_{\mathrm{p}}$, it is necessary to eliminate them. The method in detail is as follows: 

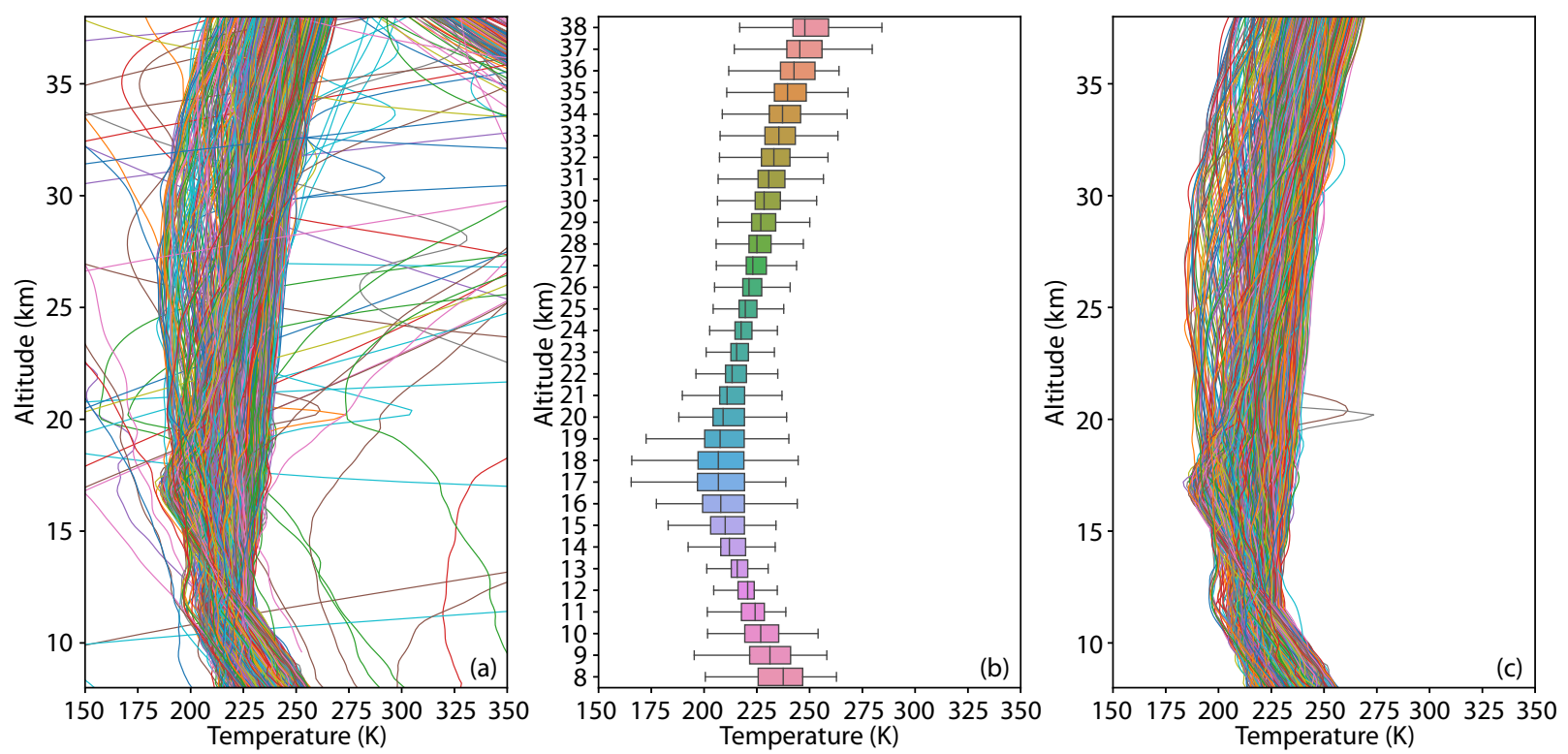

Figure 1. COSMIC RO temperature profiles on January 1, 2011 (UTC). (a) All unprocessed temperature profiles (1305 profiles in total). (b) Box-plot analysis of each level. (c) All temperature profiles after eliminating abnormal data (1094 profiles in total).

- Perform box-plot analysis on each interpolated profile at each level to provide a reasonable temperature interval for each height (Figure 1b). Temperature values that are not in the reasonable interval at each altitude level are regarded as abnormal values.

- Count the number of abnormal values in each profile. If this exceeds a certain threshold, this temperature profile is deemed to be an abnormal temperature profile that needs to be eliminated. All temperature profiles after eliminating abnormal data are shown in Figure 1c.

(c) Gridding of temperature data. A global grid is constructed at each level, and the resolution of the region is $15^{\circ} \times 10^{\circ}$ which is sparse enough to obtain the large-scale background temperature. The mean of all temperature values in the grid is taken as the temperature at the center point of the grid.

(d) Calculate large-scale waves. The S transform (Stockwell et al., 1996) is performed to extract the large-scale temperature variation at each latitude. Temperature variations with zonal wavenumbers between 0 and 6 can be regarded as large-scale waves, which include planetary waves and Kelvin waves, while the residual term (i.e., waves with zonal wavenumbers greater than 6) is considered to be mainly caused by GW activity (Jia Y et al., 2015).

(e) Obtain temperature perturbation. After interpolating the largescale temperature variation back to the position of the raw profiles as background temperature profiles (Figure 2a), temperature residuals can be obtained by subtracting background profiles from the interpolated profiles of step (b). However, the residuals still include some noise and need to be filtered by a repeat $S$ transform (Figure 2b).

After obtaining all temperature perturbation profiles, the $G W E_{p}$ at each level can be calculated by Equation (1):

$$
E_{\mathrm{p}}=\frac{1}{2}\left(\frac{g}{N}\right)^{2}\left(\frac{T^{\prime}}{\bar{T}}\right)^{2}
$$

where $g$ is the acceleration by gravity, $T^{\prime}$ is the disturbance temperature, $\bar{T}$ is the background temperature, and the Brunt-Väisälä frequency $N$ can be obtained from $N^{2}$ in Equation (2):

$$
N^{2}=\frac{g}{\bar{T}}\left(\frac{\partial \bar{T}}{\partial z}+\frac{g}{c_{p}}\right),
$$

where $z$ is the altitude and $c_{p}$ is the isobaric specific heat.

Finally, we construct a global grid with a resolution of $1^{\circ} \times 1^{\circ}$ to interpolate the scattered gravity wave $E_{\mathrm{p}}$ data into regular grid data, to obtain the gridded global GW $E_{\mathrm{p}}$ (Figure 3).

Due to the sparse distribution of COSMIC RO data at high latitudes (Figure $4 \mathrm{a}$ ), the gridded $E_{\mathrm{p}}$ may have null values in high-latitude regions. Additionally, with the gradual reduction in the quantity of COSMIC-1 daily profiles after 2011 (Luo J et al., 2018) and because the distribution of COSMIC-2 data after October 2019 is only between $60^{\circ} \mathrm{S}$ and $60^{\circ} \mathrm{N}$ (Figure 4b), to retain as much of the available data as possible, this study sets the target region as $60^{\circ} \mathrm{S}-60^{\circ} \mathrm{N}$.

\subsection{Dataset Construction and Augmentation}

\subsubsection{Dataset construction}

It is generally accepted that the main excitation conditions of atmospheric GWs include topography, deep convection, and wind shear (Fritts and Alexander, 2003). Among these excitation mechanisms, topography is the more common source of GWs (Zeng XY et al., 2017), while in equatorial and low-latitude regions, GWs induced by convection are more significant (Vincent and Alexander, 2000). Because topographic GWs are mainly generated around large terrain such as mountains, topographic data should be used as an input parameter. The wind field can reflect the fluctuation of 

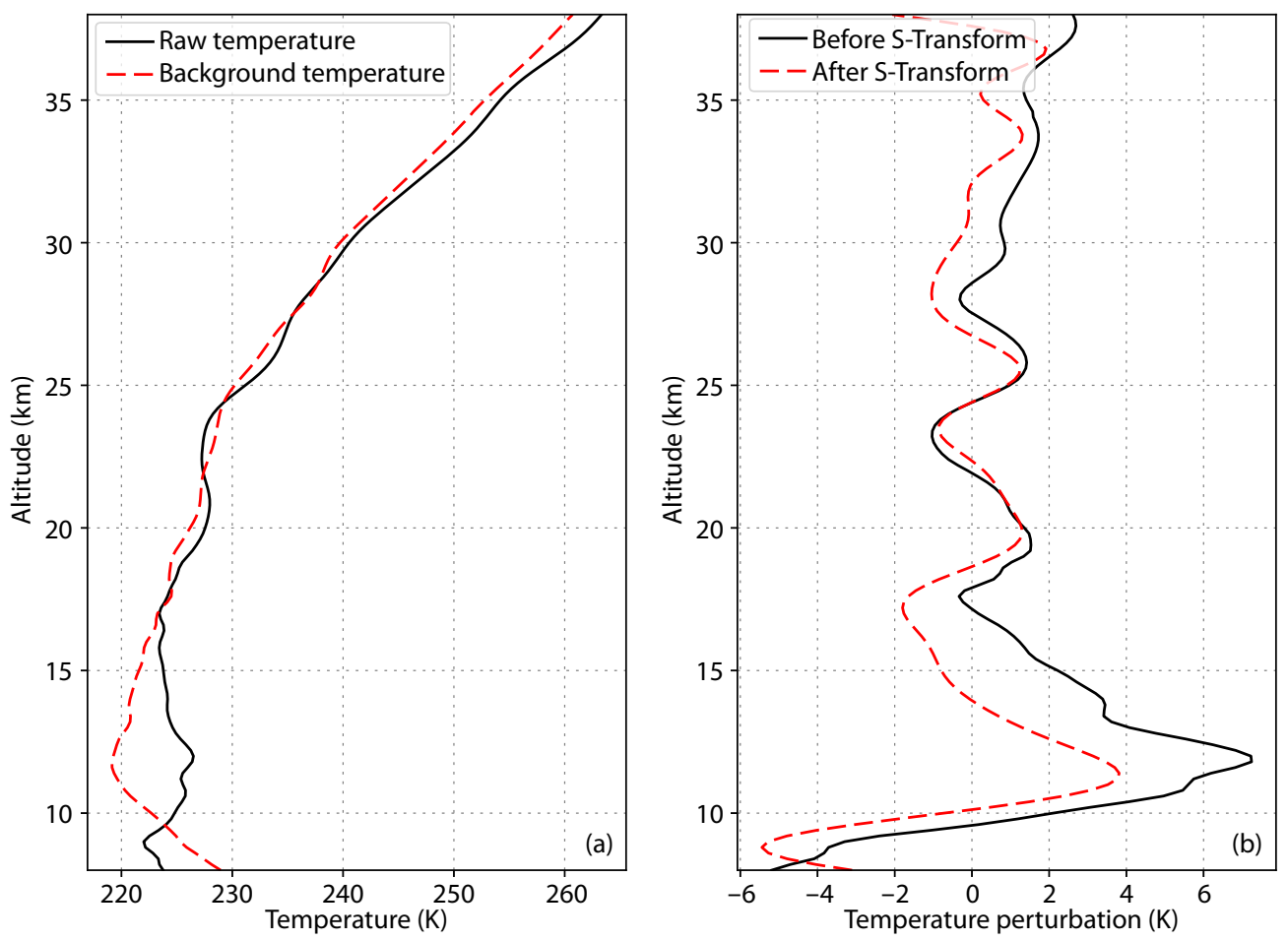

Figure 2. A COSMIC RO temperature profile obtained on January 1, 2011 (UTC). (a) Raw temperature profile and background temperature profile. (b) Temperature perturbation profile.

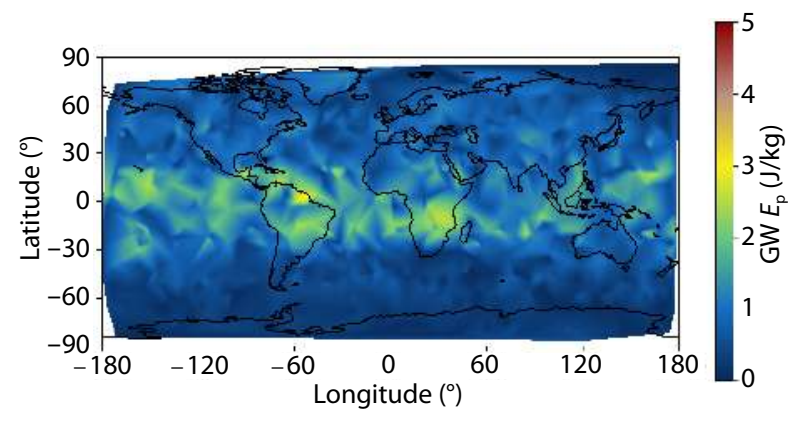

Figure 3. Gridded GW $E_{\mathrm{p}}$ averaged over $20-30 \mathrm{~km}$ on January 1, 2011 (UTC).

the atmosphere and these characteristics will be propagated upward after excitation of GWs occurs in the troposphere, therefore, the wind field should be included as an input parameter. Since strong convection is usually accompanied by high temperature and humidity, these are also included as input parameters. However, the use of only terrain, tropospheric temperature, humidity and wind fields as model inputs is not sufficient to reflect the quasi-biennial variation characteristics of GW activity (this will be illustrated in detail in the results and discussion section), therefore, it is necessary to add the stratospheric temperature field and zonal wind with QBO characteristics as inputs. It is worth mentioning that some studies indicate there is a strong correspondence between stratospheric GW $E_{\mathrm{p}}$ and zonal wind (Zeng $X Y$ et al., 2017; Xu XH et al., 2018). In Figure 5, taking the zero-wind speed line (white solid line) as the boundary, the potential energy of the east wind area in the middle latitudes surrounded by the zerowind speed line is smaller, while the potential energy of the west
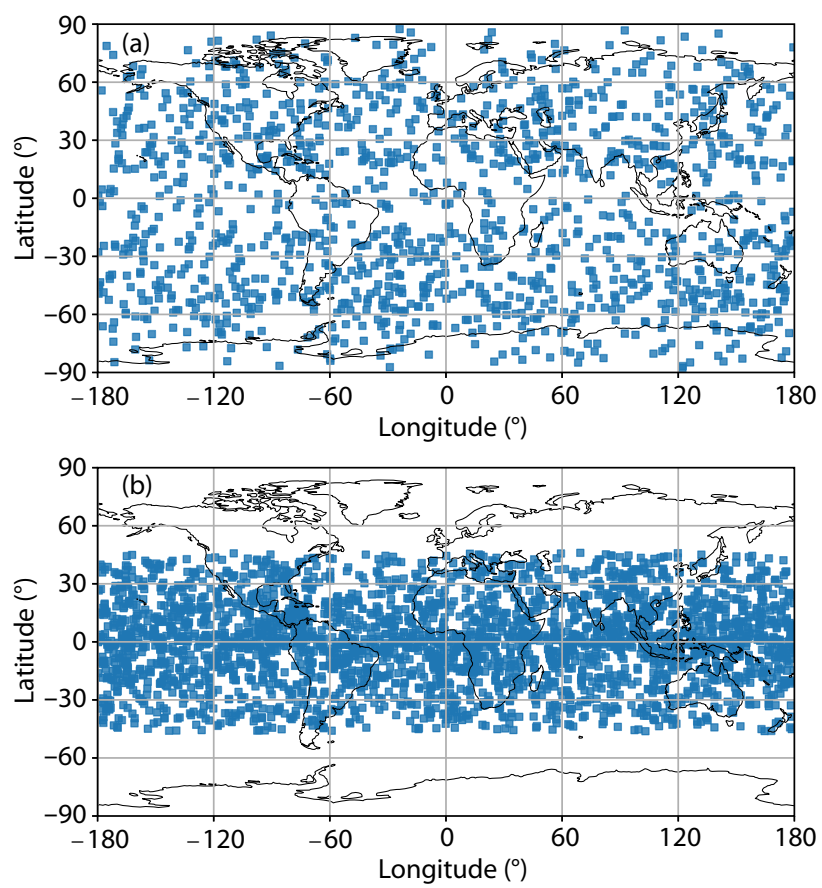

Figure 4. Distribution of COSMIC RO events on (a) January 1, 2011 (UTC) and (b) January 1, 2020 (UTC).

wind area is larger. Below the height of $20 \mathrm{~km}$, the upload of gravity wave activity is significantly affected by the zero-wind layer. In Figure 6, the maximum $E_{\mathrm{p}}$ in low latitudes appears near the zerowind speed line. The blank area regions in Figures 5 and 6 represent that $E_{\mathrm{p}}$ in these regions is greater than the maximum $(4 \mathrm{~J} / \mathrm{kg})$ 




Figure 5. The monthly average variation of GW $E_{\mathrm{p}}$ and zonal wind at each altitude in the latitude range of $30^{\circ} \mathrm{N}-40^{\circ} \mathrm{N}$ from 2007 to 2014 , from ERA5 data. The heat map is the GW $E_{\mathrm{p}}$, the isoline is the zonal wind, the negative zonal wind values (black dotted lines) represent east wind, and the positive values (red solid lines) represent west wind.

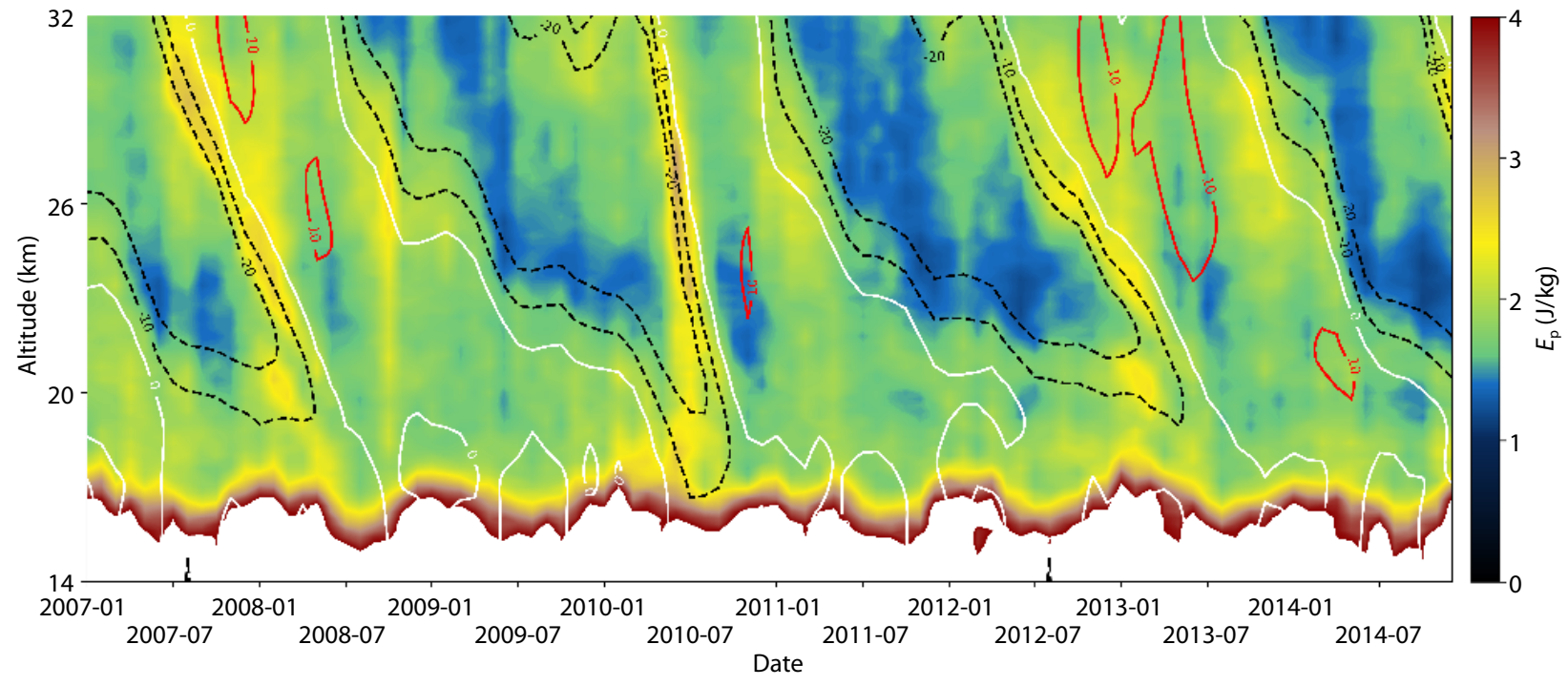

Figure 6. Same as Figure 5, but for $10^{\circ} \mathrm{S}-10^{\circ} \mathrm{N}$.

Table 1. Input dataset of the deep learning model.

\begin{tabular}{ccccc}
\hline Layer & Parameter name & Pressure levels (hPa) & Resolution & Latitude range \\
\hline 1 & Terrain & - & $1^{\circ} \times 1^{\circ}$ & $60^{\circ} \mathrm{S}-60^{\circ} \mathrm{N}$ \\
$2-4$ & Relative humidity & $500,700,850$ & $1^{\circ} \times 1^{\circ}$ & $1^{\circ} \mathrm{S}-60^{\circ} \mathrm{N}$ \\
$5-7$ & Temperature & $500,700,850$ & $1^{\circ}$ & $1^{\circ} \times 1^{\circ}$ \\
$8-10$ & Zonal wind & $500,700,850$ & $1^{\circ} \times 1^{\circ}$ & $60^{\circ} \mathrm{S}-60^{\circ} \mathrm{N}$ \\
$11-13$ & Meridional wind & $500,700,850$ & $1^{\circ} \times 1^{\circ}$ & $60^{\circ} \mathrm{S}-60^{\circ} \mathrm{N}$ \\
$14-16$ & Vertical velocity & $500,700,850$ & $1^{\circ} \times 1^{\circ}$ & $60^{\circ} \mathrm{S}-60^{\circ} \mathrm{N}$ \\
$17-19$ & Temperature & $50,100,200$ & $1^{\circ} \times 1^{\circ}$ & $60^{\circ} \mathrm{S}-60^{\circ} \mathrm{N}$ \\
$20-22$ & Zonal wind & $50,100,200$ & & $60^{\circ} \mathrm{S}-60^{\circ} \mathrm{N}$ \\
\hline
\end{tabular}


of the colorbar. The wind field data in Figure 5 and Figure 6 is from ERA5.

The input data of the deep learning model have 22 layers, and the latitude region of each layer is $60^{\circ} \mathrm{S}-60^{\circ} \mathrm{N}$. A downsampling operation is performed to achieve a resolution of $1^{\circ} \times 1^{\circ}$, which is the same as the resolution of the gridded $G W E_{\mathrm{p}}$. All input layers are shown in Table 1. The output of the model is the GW $E_{\mathrm{p}}$ grid data within the area of $60^{\circ} \mathrm{S}-60^{\circ} \mathrm{N}$.

To accelerate the convergence of the model, it is necessary to normalize the data of each layer. For the input/output layer $A$, its maximum and minimum values, max and $\min$, in the global range over the years examined can be determined, and the normalization operation for $A$ can be expressed as $\left[A-\left(\min -\varepsilon_{1}\right)\right] /$ $\left[\left(\max +\varepsilon_{2}\right)-\left(\min -\varepsilon_{1}\right)\right]$, where $\left(\min -\varepsilon_{1}\right)$ and $\left(\max +\varepsilon_{2}\right)$ represent an appropriate expansion of the value range to ensure that the normalization operation always has an input/output data value between 0 and 1 when new data are input in the model.

To verify the seasonal variation in the estimated $E_{\mathrm{p}}$, datasets from three years (June 2009 to May 2010, June 2010 to May 2011, and June 2011 to May 2012) were used as test sets to evaluate three models separately. For each model, $5 \%$ of the data outside the test set were randomly selected as the validation set and the other data were used as the training set. The date range of the training set, validation set and test set for the three models are shown in Table 2. The reason this study uses three models is to verify that the seasonality of GW $E_{\mathrm{p}}$ is not the result typical of other years, because the intensity of GW $E_{\mathrm{p}}$ is different in these three years.

\subsubsection{Dataset augmentation}

Since the calculation of the measured values of $G W E_{\mathrm{p}}$ requires all the temperature profile data from each day, only one global distribution of GW $E_{p}$ can be obtained per day. The timespan of COS-

Table 2. Date range of the training set, validation set and test set.

\begin{tabular}{ccc}
\hline Model & Training and validation set & Test set \\
\hline Model 1 & $2006.12-2009.05 \& 2010.06-2020.12$ & $2009.06-2010.05$ \\
Model 2 & $2006.12-2010.05 \& 2011.06-2020.12$ & $2010.06-2011.05$ \\
Model 3 & $2006.12-2011.05 \& 2012.06-2020.12$ & $2011.06-2012.05$ \\
\hline
\end{tabular}

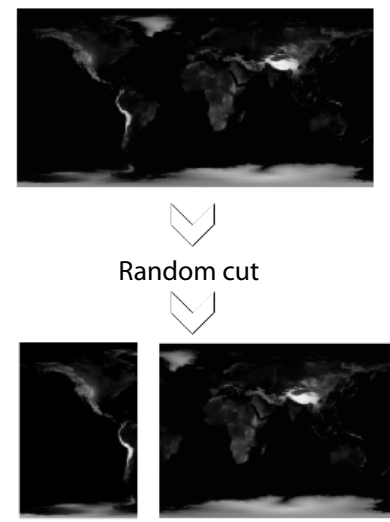

(a)

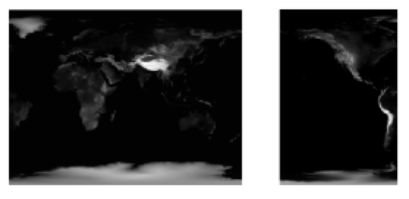

Splice



(b)
Figure 7. Steps of dataset augmentation. (a) Cut the dataset along a random longitude. (b) Swap the split dataset and re-splice them together.

MIC RO data in this paper is from January 2007 to December 2020, and the quantities of daily profiles on many days are not enough to calculate the global distribution of $G W E_{p}$, so there are only approximately 3300 valid days, which is far from enough for deep learning. Hence, it is necessary to augment the dataset.

This study develops a "cut-swap" dataset augmentation method for global meteorological data. Taking terrain data as an example, the specific steps for dataset augmentation are as follows:

(a) Select an integer longitude within the longitude range of $180^{\circ} \mathrm{W}-180^{\circ} \mathrm{E}$ and cut the dataset along that longitude (Figure 7a). (b) Swap the left and right parts of the split dataset and then resplice them together (Figure $7 \mathrm{~b}$ ).

(c) Repeat the above processes 14 times to expand the sample size to approximately 50000, which is 15 times the original amount.

The input layers (terrain and reanalysis data) and the output layer (measured $E_{\mathrm{p}}$ ) of the training set are processed simultaneously using the dataset augmentation method. Dataset augmentation can not only greatly increase the quantity of training samples but also enable the deep learning model to learn the internal relationship between terrain and GW activities. Without dataset augmentation, the terrain data input to the deep learning model is invariant.
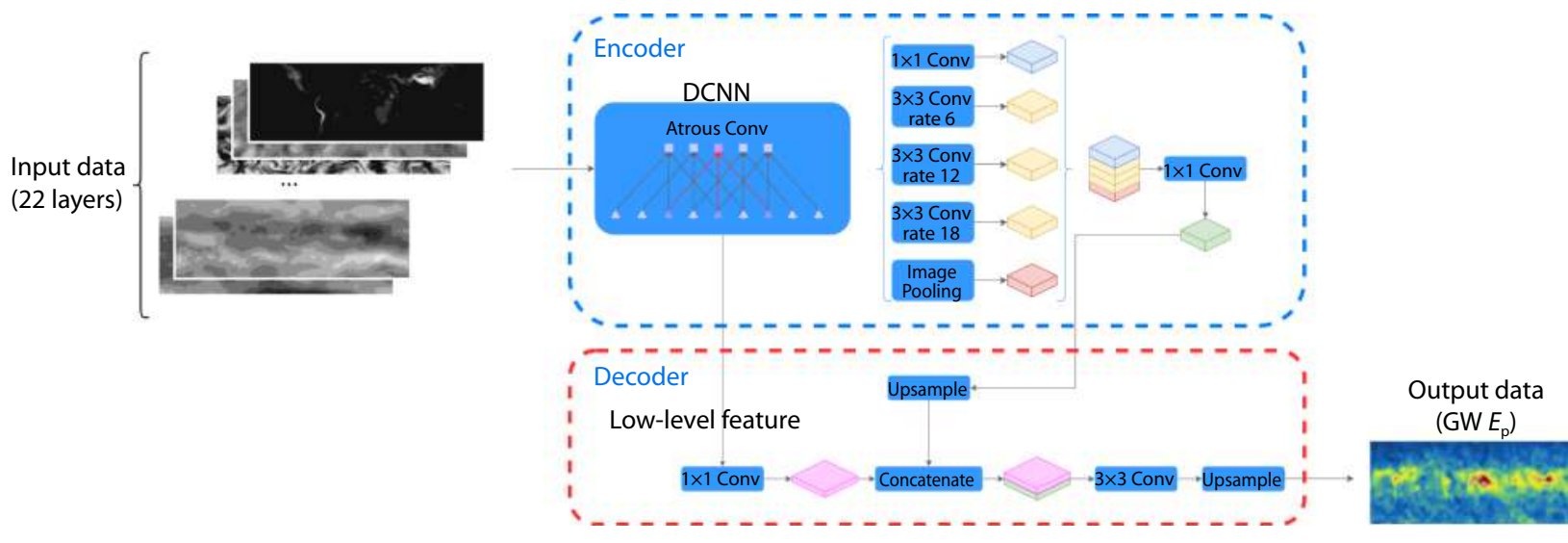

Figure 8. The model structure of DeepLab V3+. 
Such constant terrain data are not helpful to the gradient descent of the deep learning model's parameters, and cannot reflect the effect of terrain on GW activity.

\subsubsection{Deep learning model}

DeepLab is a successful deep learning model in the field of semantic segmentation and is mostly used for image classification (Chen LC et al., 2018; Ren YY et al., 2020). In this study, the DeepLab V3+ deep learning model is used to estimate stratospheric GW $E_{\mathrm{p}}$, and the ideal results are also obtained. DeepLab V3+ is mainly composed of an encoder and a decoder (the model structure is shown in Figure 8). The Adam optimizer and mean square error (MSE) loss function are used to train the model.

\section{Results and Discussion}

\subsection{Training Results}

As illustrated by Model 2, after 25 epochs of training, the losses of the training set and validation set are reduced to 0.00024 and 0.0003 , respectively (Figure 9). Since the output GW $E_{\mathrm{p}}$ of the model is normalized (the value range of the GW $E_{\mathrm{p}}$ averaged over $20-30 \mathrm{~km}$ is $0-10 \mathrm{~J} / \mathrm{kg}$ ), the calculation of the loss function uses the normalized values of $E_{\mathrm{p}}$ instead of the original values. The MSE loss function can be expressed as Equation (3).

$$
\text { MSE }=\frac{1}{m \times n} \sum_{i=1}^{m} \sum_{j=1}^{n}\left(T_{i j}-P_{i j}\right)^{2},
$$

where $T_{i j}$ is the normalized measured value of GW $E_{\mathrm{p}}$ in the $i$-th row and $j$-th column, $P_{i j}$ is the normalized estimated value of GW $E_{\mathrm{p}}$ in the $i$-th row and $j$-th column, and $m$ and $n$ are the rows and columns of $E_{\mathrm{p}}$ grid data, respectively. In this paper the values of $m$ and $n$ are 120 and 360. In Figure 9, the losses of the validation set and training set are similar, which means that the model does not overfit. The final loss of test set is 0.0009 .

Figure 10 shows the estimated results of the GW $E_{\mathrm{p}}$ averaged over 20-30 km from the 8th to the 11th of June 2010 by using the trained DeepLab V3+ model (Model 2). Taking Figure 10b as an example, some high-value areas in low latitudes and low-value areas in mid-latitudes can be found in both the measured and estimated GW $E_{\mathrm{p}}$ (shown as the marked area in Figure 10b). In the four examples selected in Figure 10, there is stronger GW $E_{\mathrm{p}}$ in the low latitudes, so the meridional mean GW $E_{\mathrm{p}}$ (both measured and estimated $E_{\mathrm{p}}$ ) of $20^{\circ} \mathrm{S}-20^{\circ} \mathrm{N}$ is calculated. The third graph of each

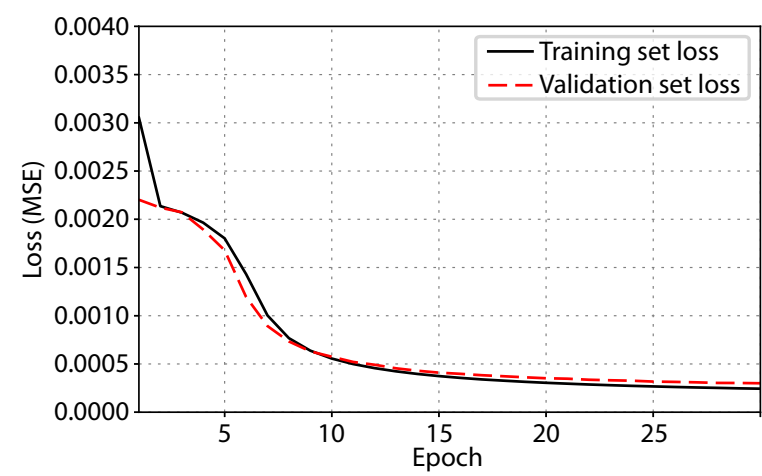

Figure 9. Losses of the training set and validation set. panel in Figure 10 also compares the measured $E_{\mathrm{p}}$ with the estimated $E_{\mathrm{p}}$ of $20^{\circ} \mathrm{S}-20^{\circ} \mathrm{N}$, and the longitudes of the extreme points of the measured and estimated $E_{\mathrm{p}}$ are almost the same (blue lines in Figure 10), which means that the zonal variation of the estimated $G W E_{\mathrm{p}}$ is generally consistent with that of the measured values.

However, Figure 10, especially Figure 10d, also shows that the error between the estimated $E_{\mathrm{p}}$ and the measured $E_{\mathrm{p}}$ in the low-latitude regions is larger than that in the mid-latitude regions. The estimated $E_{\mathrm{p}}$ is weaker than the measured $E_{\mathrm{p}}$, and a larger $E_{\mathrm{p}}$ results in a larger regional error. The five main reasons for this finding are listed below:

(a) The DeepLab model uses many convolution operations, which causes the error of the mean $E_{\mathrm{p}}$ within a certain range to be smaller and the error of a single grid point to be larger. As shown in Figure $10 \mathrm{a}-\mathrm{c}$, the estimated $E_{\mathrm{p}}$ is smaller than the measured $E_{\mathrm{p}}$ in the areas where the $E_{\mathrm{p}}$ is larger, while the meridional mean values between $20^{\circ} \mathrm{S}-20^{\circ} \mathrm{N}$ of the measured and estimated $E_{\mathrm{p}}$ are almost the same.

(b) Due to the low horizontal resolution of COSMIC RO data, large errors will inevitably occur when GW $E_{\mathrm{p}}$ calculated by temperature profiles is interpolated to a global grid with a $1^{\circ} \times 1^{\circ}$ horizontal resolution.

(c) GW $E_{\mathrm{p}}$ in the low-latitude regions is greater than that in the mid-latitudes, and the $\mathrm{RO}$ data in the equatorial and polar regions are sparser than those in the mid-latitude regions (Wang $\mathrm{L}$ and $\mathrm{Al}$ exander, 2010), so the interpolation errors in low-latitude regions tend to be amplified.

(d) To minimize the overall error in the training process, the deep learning model learns the deep correlation between the input data and $E_{\mathrm{p}}$, so the estimated value may not perfectly match the measured GW $E_{\mathrm{p}}$ in some cases. However, the overall error is lower on long time scales (such as the seasonal mean GW $E_{\mathrm{p}}$ ), which will be illustrated in the next section.

(e) Data with larger $E_{\mathrm{p}}$ account for a small proportion of the data and are underrepresented, since most of the data used for model training have smaller $E_{\mathrm{p}}$; therefore, the estimated value of the area with larger $E_{\mathrm{p}}$ will be inaccurate.

\subsection{Seasonal Variation in $\mathbf{G W} \mathbf{E}_{\mathrm{p}}$}

Due to the low horizontal resolution of daily $\mathrm{RO}$ data, the calculated daily global distribution of GW $E_{\mathrm{p}}$ is not significantly representative. Much of the related studies on the calculation of GW $E_{\mathrm{p}}$ with COSMIC RO data focus on the monthly or seasonal trend of $E_{\mathrm{p}}$ (Xu XH et al., 2018; Yu DC et al., 2019).

To verify whether the model can accurately describe the seasonal variation in stratospheric GW $E_{p}$, this study used the trained model to estimate GW $E_{\mathrm{p}}$ with the test set. The measured and estimated values of GW $E_{\mathrm{p}}$ were seasonally averaged separately. Each model uses a whole year of data as the test set, which can be divided into four seasons: JJA (Jun-Jul-Aug), SON (Sep-Oct-Nov), DJF (Dec-Jan-Feb) and MAM (Mar-Apr-May). The seasonal means of the measured and estimated GW $E_{\mathrm{p}}$ of the three models are shown in Figure 11-13. 
(a) $2010-06-08$

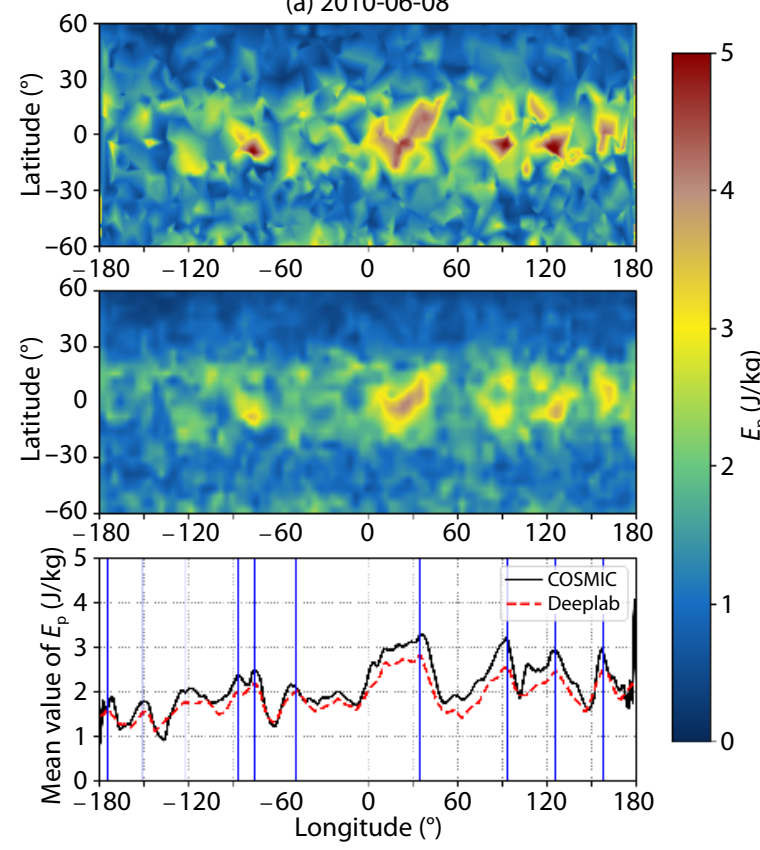

(c) 2010-06-10
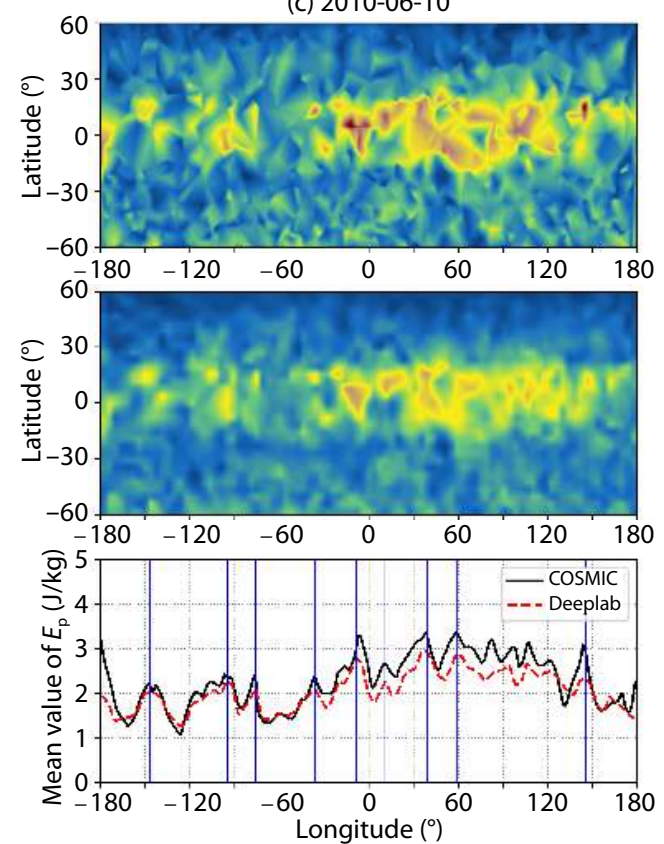

(b) 2010-06-09

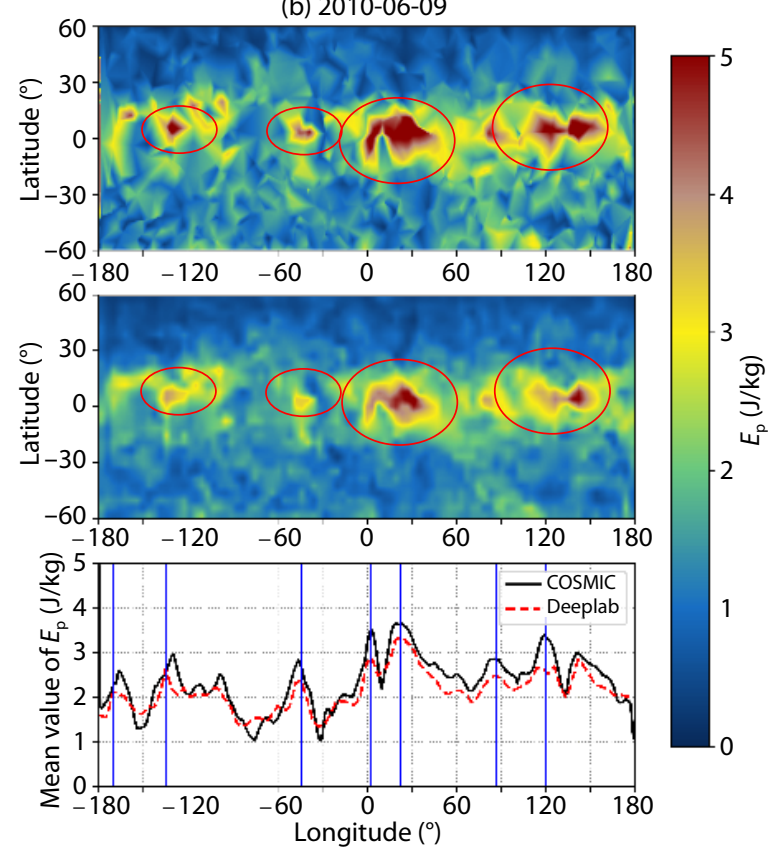

(d) 2010-06-11

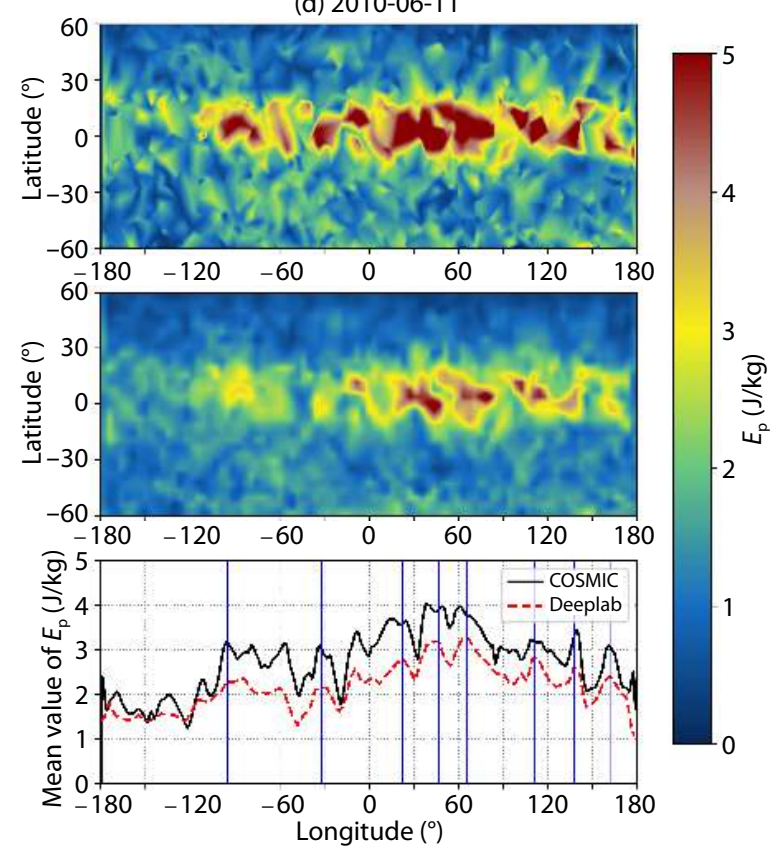

Figure 10. GW $E_{\mathrm{p}}$ averaged over 20-30 km from the 8th to the 11th of June 2010 (the three graphs of each panel from top to bottom indicate the measured GW $E_{\mathrm{p}}$, estimated GW $E_{\mathrm{p}}$ and the meridional mean GW $E_{\mathrm{p}}$ of $20^{\circ} \mathrm{S}-20^{\circ} \mathrm{N}$, respectively).

The RMSEs (root mean square errors) between the seasonal means of the measured and estimated GW $E_{\mathrm{p}}$ in JJA, SON, DJF and MAM are shown in Table 3.

$\mathrm{Xu} \mathrm{XH}$ et al. (2018) pointed out that GW $E_{\mathrm{p}}$ in the winter hemisphere is higher than that in the summer hemisphere in extratropical regions, which might be attributable to the influences of orography and zonal wind. Additionally, the GW $E_{\mathrm{p}}$ in equatorial regions is higher than that in extratropical regions. These conclusions can be confirmed by both the measured and estimated values of GW $E_{\mathrm{p}}$ in JJA and DJF of Figure 11-13. The Southern Hemisphere is the winter hemisphere in Figure $12 \mathrm{a}$, and the GW $E_{\mathrm{p}}$ in the mid-latitude regions of the Southern Hemisphere is significantly higher than that in the mid-latitude regions of the Northern Hemisphere, while Figure 12c shows the opposite phenomenon. In terms of seasonal distribution characteristics of GW $E_{\mathrm{p}}$, there are also some research results of SABER/TIMED satellites (Zhang $Y$ et al., 2012). Compared with the seasonal distribution of $E_{\mathrm{p}}$ in the study by Zhang $Y$ et al. (2012), our research results are slightly different, e.g., the $E_{\mathrm{p}}$ in mid-latitudes during winter in their study is stronger than shown in this study. This may be due to different data sources and processing methods.

In addition, in the two seasons of JJA and SON, GW $E_{\mathrm{p}}$ is stronger 

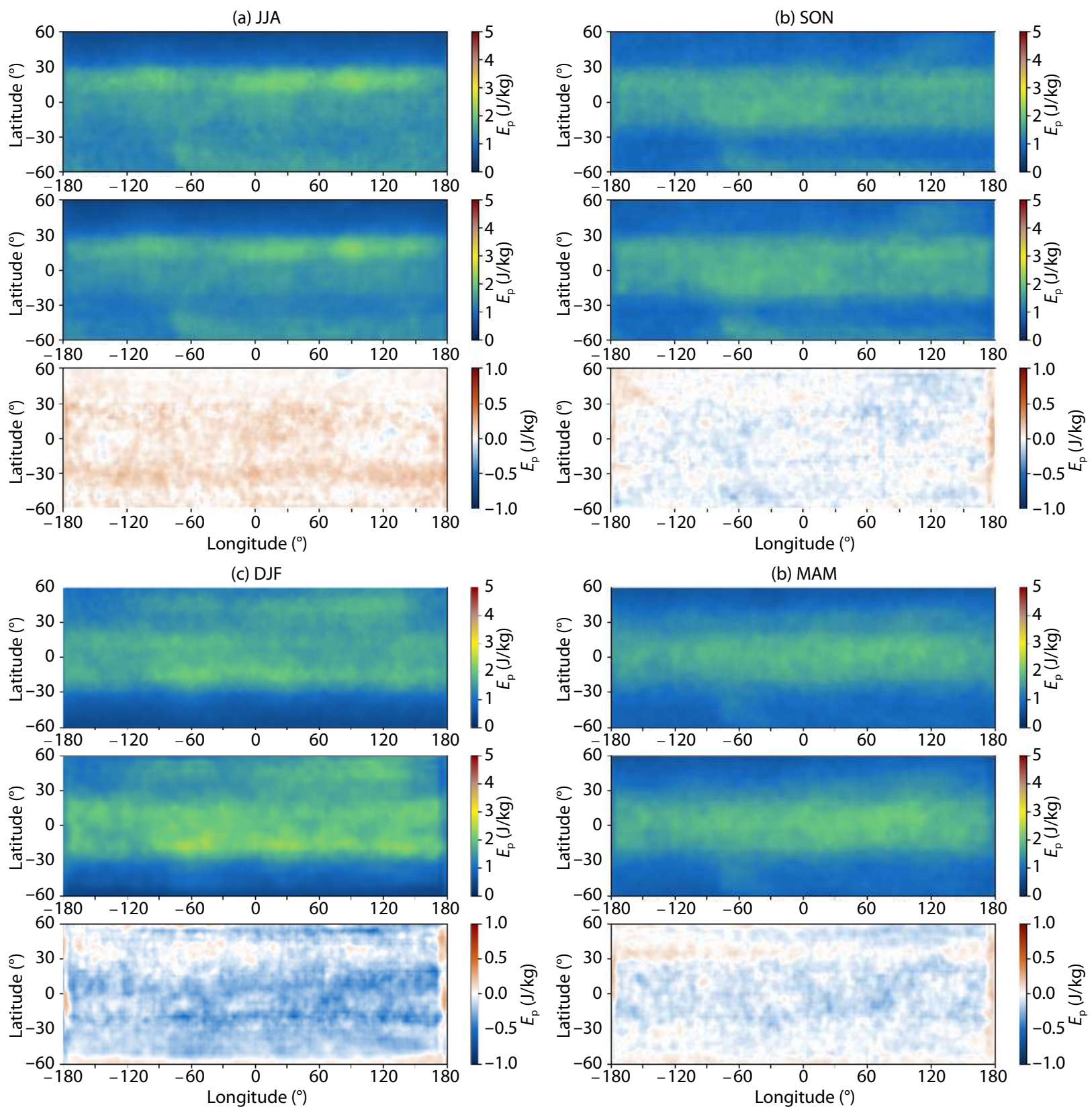

Figure 11. Seasonal means of GW $E_{\mathrm{p}}$ over 20-30 km from Jun 2009 to May 2010 by Model 1 (the three graphs of each panel from top to bottom indicate the measured GW $E_{\mathrm{p}}$, estimated GW $E_{\mathrm{p}}$ and error between the measured and estimated $E_{\mathrm{p}}$, respectively).

near $80^{\circ} \mathrm{W}$ in the southern hemisphere, and it extends eastward. This is due to the GW activity caused by the topography of the Andes mountains in South America. Figures 11-13 show that these three models all can accurately estimate the GW $E_{\mathrm{p}}$ in this area, which also demonstrates that the deep learning model used in this study can learn the influence of terrain on GW activity.

Figures 11-13 also show that the GW activity of JJA in 2010 was significantly stronger than in 2009 and 2011, and the estimated model results also correctly reflect this intensity variation. Additionally, the RMSEs between the seasonal average values of the measured and estimated $E_{\mathrm{p}}$ are small, which indicates that the method used in this paper can accurately reflect the seasonal variation characteristics of GW activity.

\subsection{Quasi-biennial Oscillation of GW $E_{\mathrm{p}}$}

QBO usually refers to the phenomenon where the tropical lower stratospheric zonal wind alternates between easterly and westerly directions. This phenomenon also occurs in the stratospheric GW $E_{\mathrm{p}}$ in low-latitude regions ( $\mathrm{Xu} \mathrm{XH}$ et al., 2018). The QBO of $E_{\mathrm{p}}$ calculated by COSMIC RO data from 2007-01 to 2013-12 is shown in Figure 14. A 13-month moving average is performed to remove the annual change, so that the $\mathrm{QBO}$ results will be clearer.

In this study, to enable the deep learning model to learn the QBO characteristics, the temperature and zonal wind fields at 50,100, and $200 \mathrm{hPa}$ of the ERA5 reanalysis dataset need to be added to the input data, since these wind fields in the stratosphere have significant influence on QBO characteristics. 
(a) JJA

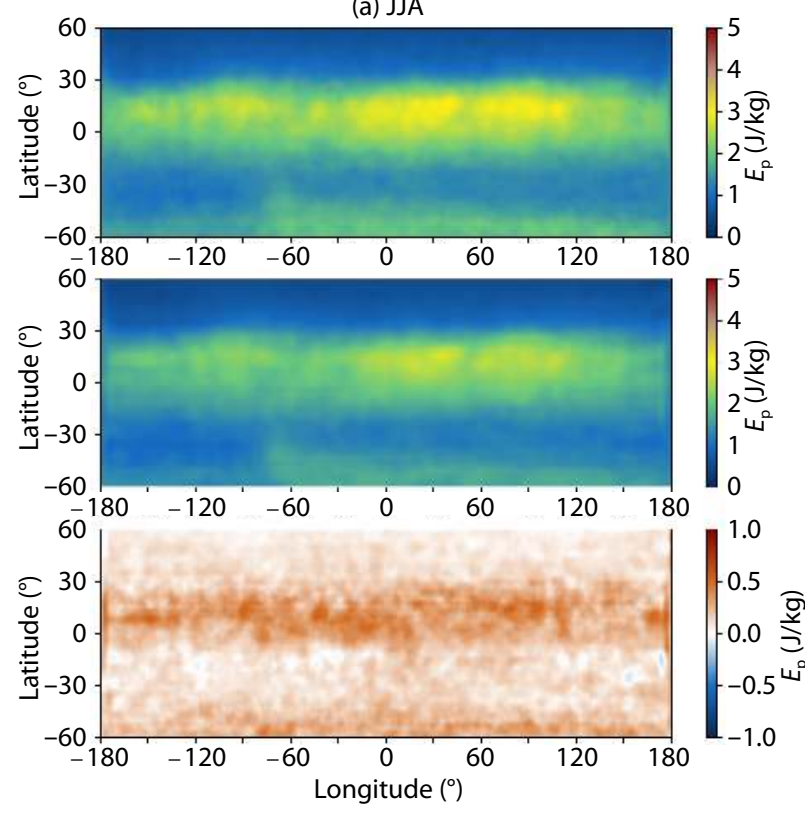

(c) DJF
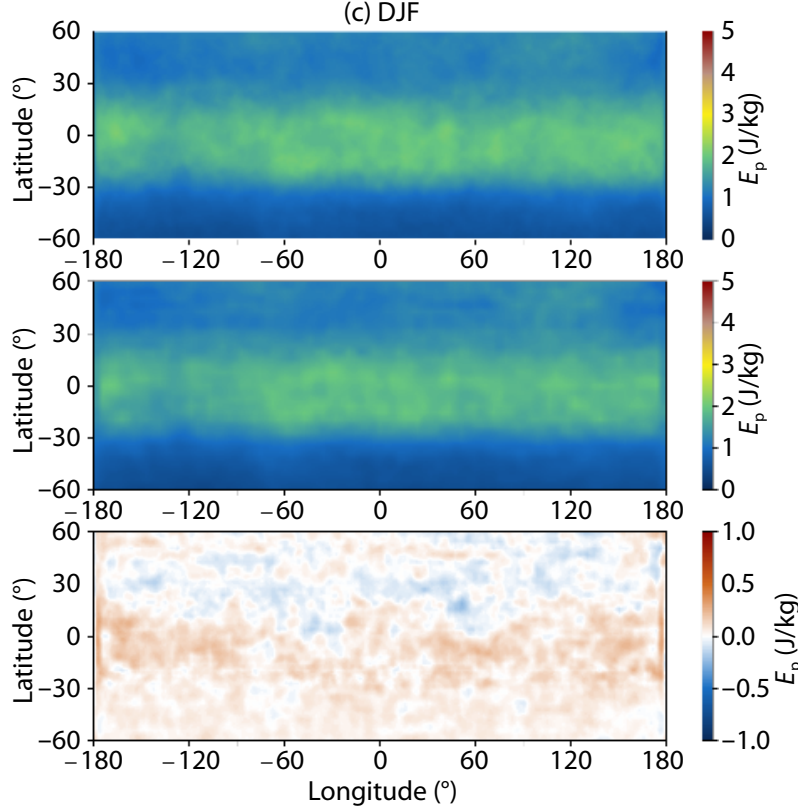

(b) SON
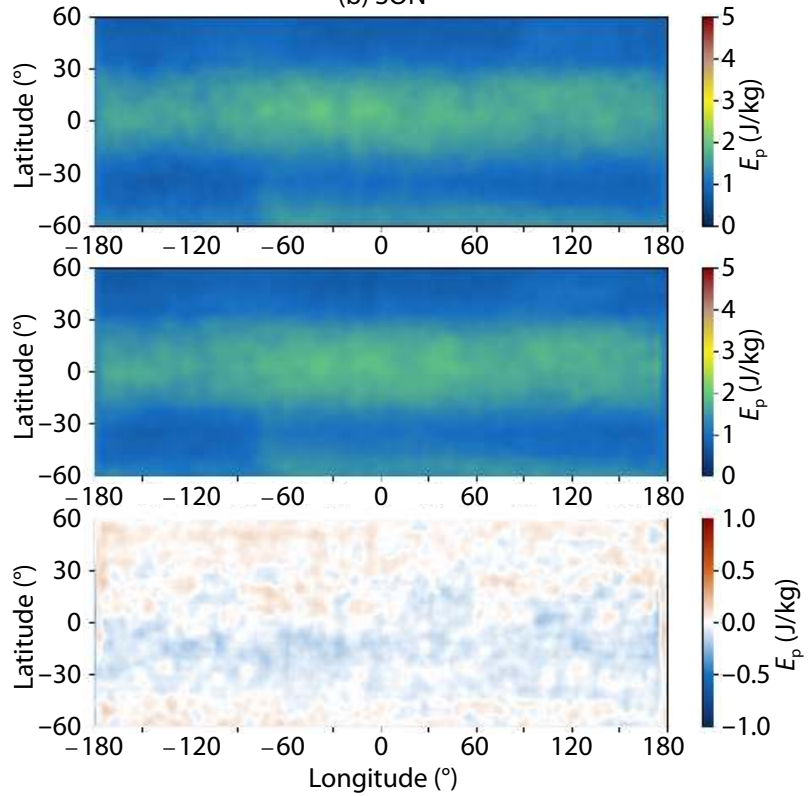

(b) MAM
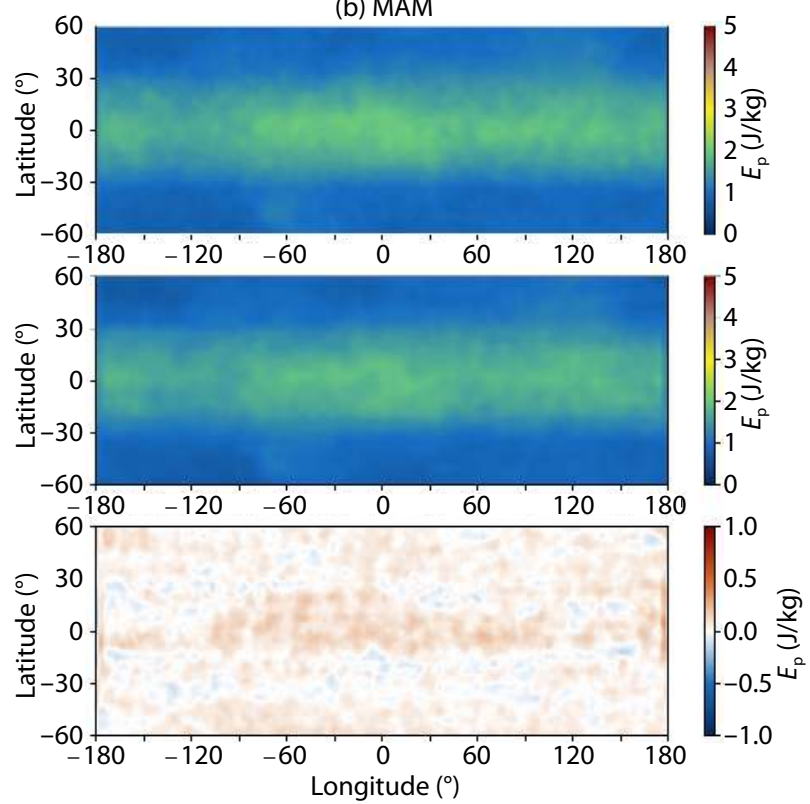

Figure 12. Same as Figure 11, but for seasonal means of GW $E_{\mathrm{p}}$ over 20-30 km from Jun 2010 to May 2011 by Model 2.

As illustrated by the example of Model 2, to verify whether the model can describe the QBO effect of stratospheric GW $E_{\mathrm{p}}$ in lowlatitude regions, this study uses the deep learning model to estimate the GW $E_{\mathrm{p}}$ from 2000 to 2006 (since the data after 2007 are involved in the training of the model, even if the estimated $E_{\mathrm{p}}$ after 2007 exhibits QBO characteristics, it does not indicate that the model actually learns them). Figure 15 shows the estimated $E_{\mathrm{p}}$ from 2000-01 to 2006-12 output by the deep learning model.

As shown in Figure 14, the measured $E_{\mathrm{p}}$ from 2007 to 2013 shows a significant $\mathrm{QBO}$ effect in low-latitude regions, and strong years and weak years of GW $E_{\mathrm{p}}$ alternately appear in low-latitude regions. Additionally, QBO occurs in the estimated $E_{\mathrm{p}}$ from 2000 to 2006, as shown in Figure 15. Although the model is unable to obtain measured values of GW $E_{\mathrm{p}}$ from 2000 to 2006 for comparison, it appears that the trained model has learned the QBO characteristics of GWs. Although the model can predict the QBO characteristics of $E_{\mathrm{p}}$, its QBO amplitude may be less than that of the measured $E_{\mathrm{p}}$ (Figure $14 \mathrm{c}$ and $15 \mathrm{c}$ ), which means that the model cannot perfectly estimate the long-term variation of GW $E_{\mathrm{p}}$.

The QBO characteristics of $E_{\mathrm{p}}$ can be learned by the model mainly because the stratospheric temperature and zonal wind in the input parameters of the model also have QBO characteristics. When the stratospheric temperature and zonal wind (layers 17-22) in the input parameters are omitted, the resulting estimated average GW $E_{\mathrm{p}}$ of 20-30 km from 2000-01 to 2006-12 is shown in Figure 16 , and there is no obvious quasi-biennial variation in the low-latitude region. 

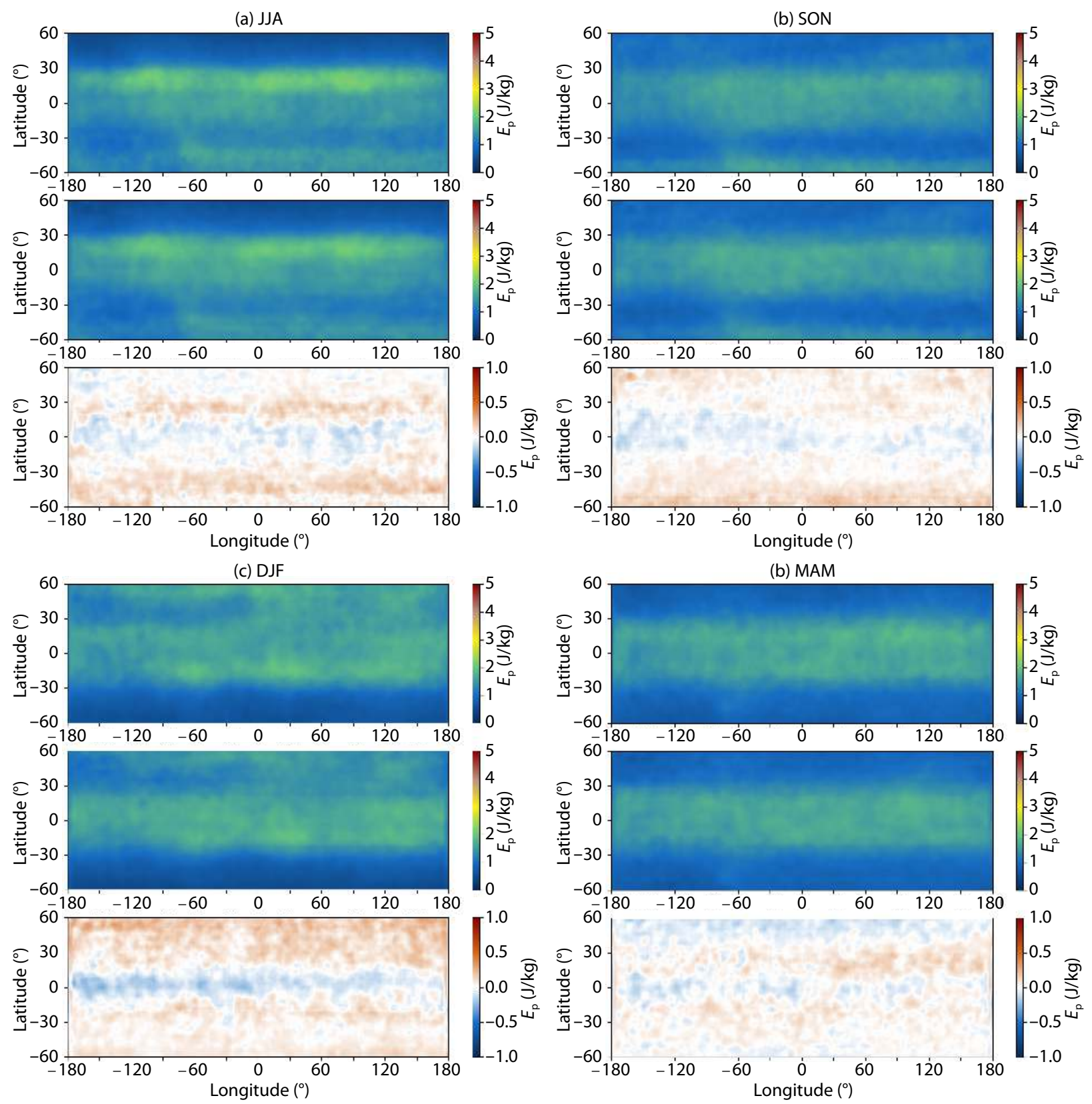

Figure 13. Same as Figure 11, but for seasonal means of GW $E_{\mathrm{p}}$ over 20-30 km from Jun 2011 to May 2012 by Model 3.

Table 3. RMSEs between the seasonal means of the measured and estimated GW $E_{\mathrm{p}}$.

\begin{tabular}{ccccc}
\hline \multirow{2}{*}{ Model } & \multicolumn{4}{c}{ RMSE $(\mathrm{J} / \mathrm{kg})$} \\
\cline { 2 - 5 } & JJA & SON & DJF & MAM \\
\hline Model 1 & 0.089 & 0.063 & 0.193 & 0.085 \\
Model 2 & 0.2 & 0.06 & 0.074 & 0.062 \\
Model 3 & 0.074 & 0.068 & 0.1 & 0.06 \\
\hline
\end{tabular}

\section{Conclusions}

In this paper, a DeepLab V3+ deep learning model is applied to estimate stratospheric GW potential energy. Using direct mapping from the reanalysis data at $50,100,200,500,700$ and $850 \mathrm{hPa}$ and terrain data to the GW $E_{\mathrm{p}}$ averaged over $20-30 \mathrm{~km}$ can be realized.

Since the sources of GWs are mainly terrain, wind shear and deep convection, temperature, wind field, and relative humidity in the troposphere $(500,700,850 \mathrm{hPa})$ are considered as the input of the model. To reflect the $\mathrm{QBO}$ characteristics of GWs, temperature and zonal wind fields at 50,100 and $200 \mathrm{hPa}$ need to be added to the input data. A "cut-swap" approach is applied to augment the dataset. Additionally, this augmentation method can make the input terrain data changeable, which may help the model learn the relationship between terrain and GW activities.

The results show the following:

(1) This deep learning method can effectively estimate the zonal trend of the GW $E_{\mathrm{p}}$ averaged over 20-30 km. However, the errors in low-latitude regions are larger than those in mid-latitude re- 


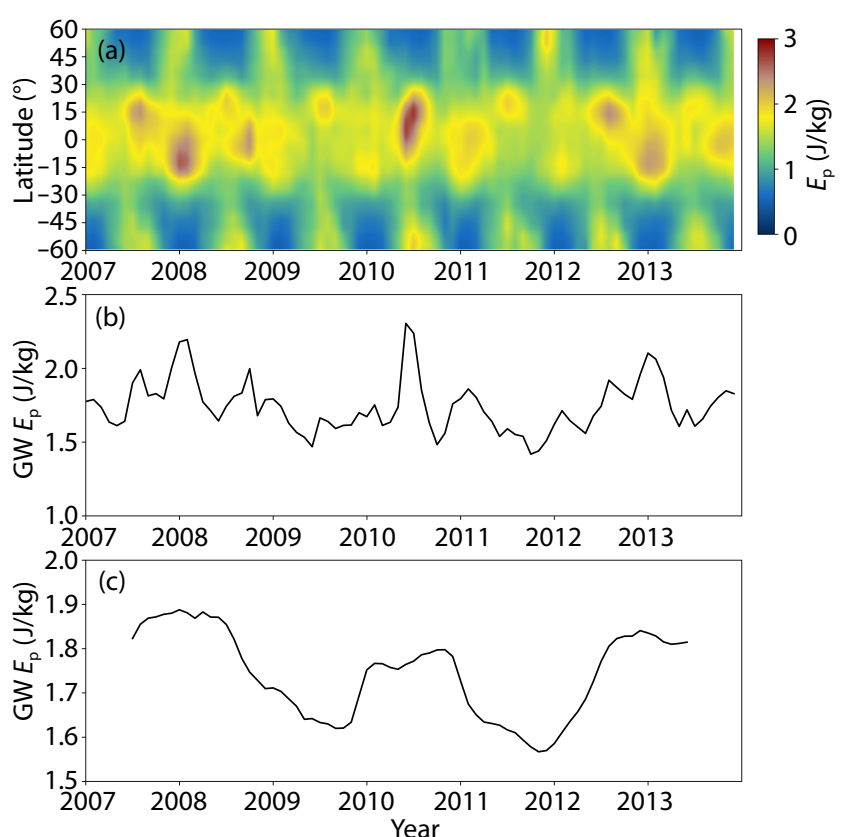

Figure 14. Measured $E_{\mathrm{p}}$ from 2007.01 to 2013.12 calculated by COSMIC RO data. (a) Variation in zonal mean GW $E_{\mathrm{p}}$ with time. (b) Variation in the mean $G W E_{\mathrm{p}}$ within the latitude range of $20^{\circ} \mathrm{S}-20^{\circ} \mathrm{N}$ with time. (c) The mean GW $E_{\mathrm{p}}$ within the latitude range of $20^{\circ} \mathrm{S}-20^{\circ} \mathrm{N}$ after 13-month moving average processing.

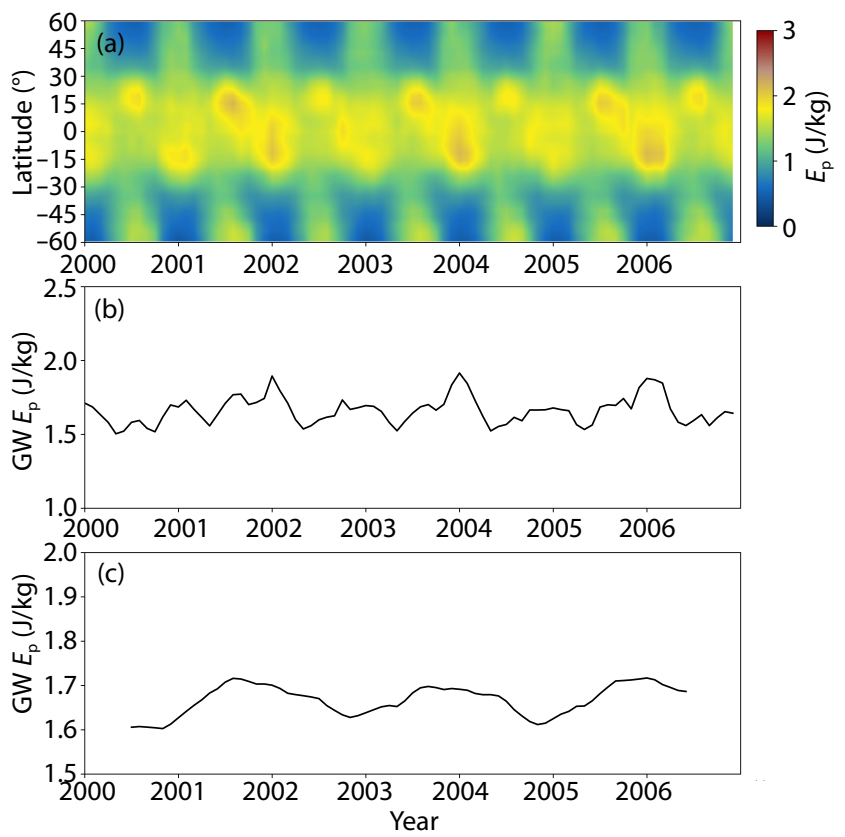

Figure 15. Estimated $E_{\mathrm{p}}$ from 2000-01 to 2006-12 according to Model 2. (a) Variation in zonal mean GW $E_{\mathrm{p}}$ over time. (b) Variation in the mean GW $E_{\mathrm{p}}$ within the latitude range of $20^{\circ} \mathrm{S}-20^{\circ} \mathrm{N}$ over time. (c) The mean GW $E_{\mathrm{p}}$ within the latitude range of $20^{\circ} \mathrm{S}-20^{\circ} \mathrm{N}$ after $13-$ month moving average processing.

gions. The main reason is that the large number of convolution operations used in the deep learning model causes the error of the mean $E_{\mathrm{p}}$ within a certain range to decrease and the error of a
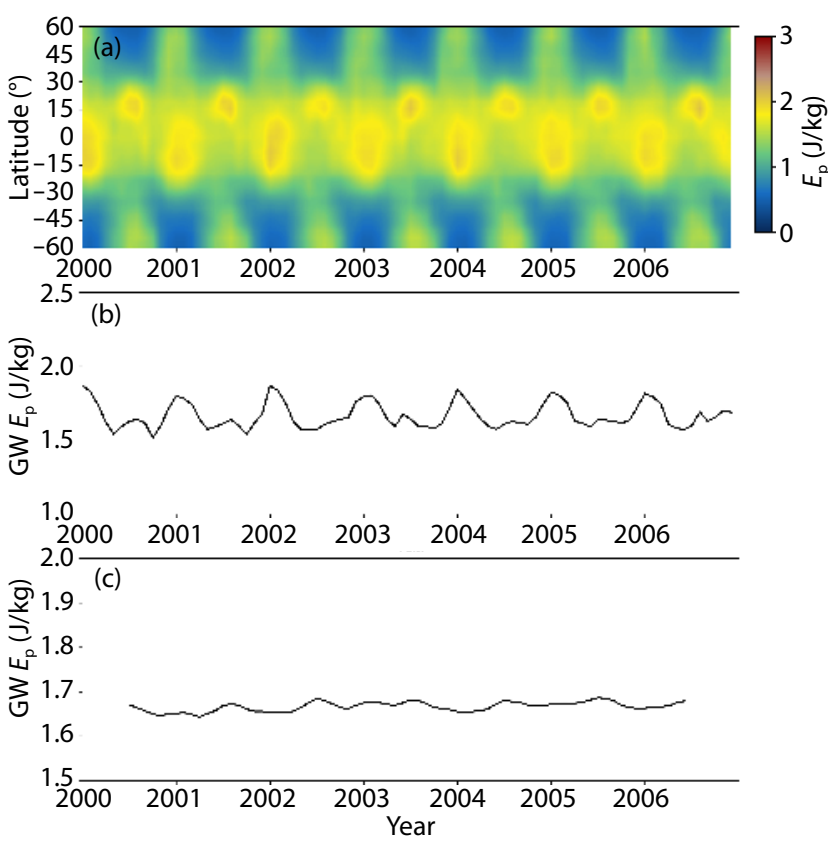

Figure 16. Estimated $E_{\mathrm{p}}$ from 2000-01 to 2006-12 by the DeepLab $\mathrm{V} 3+$ model without stratospheric temperature and zonal wind. (a) Variation in zonal mean GW $E_{\mathrm{p}}$ with time. (b) Variation in the mean $G W E_{p}$ within the latitude range of $20^{\circ} \mathrm{S}-20^{\circ} \mathrm{N}$ with time. (c) The mean GW $E_{\mathrm{p}}$ within the latitude range of $20^{\circ} \mathrm{S}-20^{\circ} \mathrm{N}$ after 13 -month moving average processing.

single grid point to increase. In addition, the horizontal resolution of COSMIC RO data is low, and the RO data at low latitudes are sparser than those at middle latitudes, so the interpolation process of constructing the grid data of measured $E_{\mathrm{p}}$ tends to cause larger errors at low latitudes. These errors also have a great impact on the accuracy of model training.

(2) The estimated results of the model show significant seasonal variations in which GW activity is strong in winter and weak in summer. The seasonal variation reflected in the estimated $E_{\mathrm{p}}$ is consistent with the measured $E_{\mathrm{p}}$ calculated by COSMIC RO temperature profiles.

(3) This model can learn the QBO characteristics of GWs. With the input of reanalysis data from 2000 to 2006 and terrain data, the average $G W E_{\mathrm{p}}$ at heights of $20-30 \mathrm{~km}$ during these seven years estimated by the deep learning model shows significant QBO characteristics.

The significance of this study is the verification of the deep learning method to estimate GW $E_{\mathrm{p}}$. Abundant reanalysis data can be used to estimate stratospheric GW $E_{\mathrm{p}}$ in recent decades so that the long-term variation in stratospheric GWs in mid- and low-latitude regions can be determined. Additionally, for future studies, numerical prediction can also be considered as inputs of the deep learning model to realize the prediction of GW $E_{\mathrm{p}}$.

\section{Acknowledgments}

This study was supported by the "Western Light" Cross-Team Project of Chinese Academy of Sciences, Key Laboratory Cooperative Research Project. We would like to thank all the editors and 
the anonymous reviewers for their help in the development and improvement of this paper. The COSMIC RO data was downloaded from https://cdaac-www.cosmic.ucar.edu/. The GMTED2010 terrain data was downloaded from https://www.usgs.gov/ core-science-systems/eros/coastal-changes-and-impacts/ gmted2010. The ERA5 hourly data on pressure levels was downloaded from https://cds.climate.copernicus.eu/cdsapp\#!/dataset/ reanalysis-era5-pressure-levels.

\section{References}

Alexander, M. J. (1996). A simulated spectrum of convectively generated gravity waves: propagation from the tropopause to the mesopause and effects on the middle atmosphere. J. Geophys. Res. :Atmos., 101(D1), 1571-1588. https://doi.org/10.1029/95jd02046

Alexander, M. J. (1998). Interpretations of observed climatological patterns in stratospheric gravity wave variance. J. Geophys. Res. :Atmos., 103(D8), 8627-8640. https://doi.org/10.1029/97JD03325

Alexander, M. J., Gille, J., Cavanaugh, C., Coffey, M., Craig, C., Eden, T., Francis, G., Halvorson, C., Hannigan, J., ... Dean, V. (2008). Global estimates of gravity wave momentum flux from High Resolution Dynamics Limb Sounder observations. J. Geophys. Res. :Atmos., 113(D15), D15S18. https://doi.org/10.1029/2007JD008807

Bai, W. H., Deng, N., Sun, Y. Q., Du, Q. F., Xia, J. M., Wang, X. Y., Meng, X. G., Zhao, D. Y., Liu, C. L., ... Liu, X. X. (2020). Applications of GNSS-RO to numerical weather prediction and tropical cyclone forecast. Atmosphere, 11(11), 1204. https://doi.org/10.3390/atmos11111204

Chen, D., Chen, Z. Y., and Lü, D. R. (2012). Simulation of the stratospheric gravity waves generated by the Typhoon Matsa in 2005. Sci. China Earth Sci., 55(4), 602-610. https://doi.org/10.1007/s11430-011-4303-1

Chen, D., Chen, Z. Y., and Lü, D. R. (2013). Spatiotemporal spectrum and momentum flux of the stratospheric gravity waves generated by a typhoon. Sci. China Earth Sci., 56(1), 54-62. https://doi.org/10.1007/s11430012-4502-4

Chen, L. C., Papandreou, G., Kokkinos, I., Murphy, K., and Yuille, A. L. (2018). DeepLab: semantic image segmentation with deep convolutional nets, Atrous convolution, and fully connected CRFs. IEEE Trans. Pattern Anal. Mach. Intell., 40(4), 834-848. https://doi.org/10.1109/TPAMI.2017.2699184

Chen, Z. P., Li, J. C., Luo, J., and Cao, X. Y. (2018). A new strategy for extracting ENSO related signals in the troposphere and lower stratosphere from GNSS RO specific humidity observations. Remote Sens., 10(4), 503. https://doi.org/10.3390/rs10040503

Cheng, N., Song, S. L., Jiao, G. Q., Jin, X. L., and Li, W. (2021). Global monitoring of geomagnetic storm-induced ionosphere anomalies using 3-D ionospheric modeling with multi-GNSS and COSMIC measurements. Radio Sci., 56(2), e2020RS007074. https://doi.org/10.1029/2020RS007074

Fritts, D. C., and Alexander, M. J. (2003). Gravity wave dynamics and effects in the middle atmosphere. Rev. Geophys., 41(1), 3-1-3-64. https://doi.org/10.1029/2001RG000106

Hamilton, K. (1991). Climatological statistics of stratospheric inertia-gravity waves deduced from historical rocketsonde wind and temperature data. J. Geophys. Res. :Atmos., 96(D11), 20831-20839. https://doi.org/10.1029/91JD02188

Jia, Y., Zhang, S. D., Yi, F., Huang, C. M., Huang, K. M., Gan, Q., and Gong, Y. (2015). Observations of gravity wave activity during stratospheric sudden warmings in the Northern Hemisphere. Sci. China Technol. Sci., 58(6), 951-960. https://doi.org/10.1007/s11431-015-5806-3

John, S. R., and Kumar, K. K. (2012). TIMED/SABER observations of global gravity wave climatology and their interannual variability from stratosphere to mesosphere lower thermosphere. Climate Dyn., 39(6), 1489-1505. https://doi.org/10.1007/s00382-012-1329-9

Kramer, R., Wüst, S., and Bittner, M. (2016). Investigation of gravity wave activity based on operational radiosonde data from 13 years (1997-2009): climatology and possible induced variability. J. Atmos. Solar-Terr. Phys., 140, 23-33. https://doi.org/10.1016/j.jastp.2016.01.014

Liu, X., Xu, J. Y., Yue, J., Vadas, S. L., and Becker, E. (2019). Orographic primary and secondary gravity waves in the middle atmosphere from 16-year SABER observations. Geophys. Res. Lett., 46(8), 4512-4522. https://doi.org/10.1029/2019gl082256

Luo, J., Chen, Z. P., and Xu, X. H. (2018). Specific humidity response in the troposphere and lower stratosphere to ONI revealed by COSMIC observations. Chin. J. Geophys., 61(2), 466-476. https://doi.org/10.6038/cjg2018L0201

Matsuoka, D., Watanabe, S., Sato, K., Kawazoe, S., Yu, W., and Easterbrook, S. (2020). Application of deep learning to estimate atmospheric gravity wave parameters in reanalysis data sets. Geophys. Res. Lett., 47(19), e2020GL089436. https://doi.org/10.1029/2020GL089436

Meyer, C. I., Ern, M., Hoffmann, L., Trinh, Q. T., and Alexander, M. J. (2018). Intercomparison of AIRS and HIRDLS stratospheric gravity wave observations. Atmos. Meas. Tech., 11(1), 215-232. https://doi.org/10.5194/amt-11-215-2018

Moraux, A., Dewitte, S., Cornelis, B., and Munteanu, A. (2019). Deep learning for precipitation estimation from satellite and rain gauges measurements. Remote Sens., 11(21), 2463. https://doi.org/10.3390/rs11212463

Rasp, S., Pritchard, M. S., and Gentine, P. (2018). Deep learning to represent subgrid processes in climate models. Proc. Natl. Acad. Sci. USA, 115(39), 9684-9689. https://doi.org/10.1073/pnas.1810286115

Ren, Y. Y., Zhang, X. F., Ma, Y. J., Yang, Q. Y., Wang, C. J., Liu, H. L., and Qi, Q. (2020). Full convolutional neural network based on multi-scale feature fusion for the class imbalance remote sensing image classification. Remote Sens., 12(21), 3547. https://doi.org/10.3390/rs12213547

Scher, S. (2018). Toward data-driven weather and climate forecasting: approximating a simple general circulation model with deep learning. Geophys. Res. Lett., 45(22), 12616-12622. https://doi.org/10.1029/2018gl080704

Stockwell, R. G., Mansinha, L., and Lowe, R. P. (1996). Localization of the complex spectrum: the S transform. IEEE Trans. Signal Process., 44(4), 998-1001. https://doi.org/10.1109/78.492555

Vincent, R. A., and Alexander, M. J. (2000). Gravity waves in the tropical lower stratosphere: an observational study of seasonal and interannual variability. J. Geophys. Res. :Atmos., 105(D14), 17971-17982. https://doi.org/10.1029/2000JD900196

Wang, L., and Alexander, M. J. (2009). Gravity wave activity during stratospheric sudden warmings in the 2007-2008 Northern Hemisphere winter. J. Geophys. Res. :Atmos., 114(D18), D18108. https://doi.org/10.1029/2009JD011867

Wang, L., and Alexander, M. J. (2010). Global estimates of gravity wave parameters from GPS radio occultation temperature data. J. Geophys. Res. :Atmos., 115(D21), D21122. https://doi.org/10.1029/2010JD013860

Xu, X. H., Guo, J. C., and Luo, J. (2015). Analysis of the global distribution of the atmospheric gravity wave parameters using COSMIC radio occultation data. Geomat. Inf. Sci. Wuhan Univ., 40(11), 1493-1498. https://doi.org/10.13203/j.whugis20130587

Xu, X. H., Yu, D. C., and Luo, J. (2018). The spatial and temporal variability of global stratospheric gravity waves and their activity during sudden stratospheric warming revealed by COSMIC measurements. Adv. Atmos. Sci., 35(12), 1533-1546. https://doi.org/10.1007/s00376-018-5053-1

Yoshiki, M., and Sato, K. (2000). A statistical study of gravity waves in the polar regions based on operational radiosonde data. J. Geophys. Res. :Atmos., 105(D14), 17995-18011. https://doi.org/10.1029/2000jd900204

Yu, D. C., Xu, X. H., Luo, J., and Li, J. (2019). On the relationship between gravity waves and tropopause height and temperature over the globe revealed by COSMIC radio occultation measurements. Atmosphere, 10(2), 75. https://doi.org/10.3390/atmos10020075

Zeng, X. Y., Xue, X. H., and Dou, X. K., Liang, C., and Jia, M. J. (2017). COSMIC GPS observations of topographic gravity waves in the stratosphere around the Tibetan Plateau. Sci. China Earth Sci., 60(1), 188-197. https://doi.org/10.1007/s11430-016-0065-6

Zhang, Y., Xiong, J., Liu, L., and Wan, W. (2012). A global morphology of gravity wave activity in the stratosphere revealed by the 8-year SABER/TIMED data. J. Geophys. Res. :Atmos., 117(D21), D21101. https://doi.org/10.1029/2012jd017676

Zhao, R. C., Dou, X. K., Sun, D. S., Xue, X. H., Zheng, J., Han, Y. L., Chen, T. D., Wang, G. C., and Zhou, Y. J. (2016). Gravity waves observation of wind field in stratosphere based on a Rayleigh Doppler lidar. Opt. Express, 24(6), A581-A591. https://doi.org/10.1364/OE.24.00A581 